\title{
Article \\ Immobilised Humic Substances as Low-Cost Sorbents for Emerging Contaminants
}

\author{
Linda Ansone-Bertina ${ }^{1, *(\mathbb{D})}$, Karina Upska ${ }^{1}$, Linda Dobkevica ${ }^{1}$, Jorens Kviesis ${ }^{1}$, Raimonds Meija ${ }^{2,3}$ \\ and Maris Klavins ${ }^{1}$ (D) \\ 1 Department of Environmental Science, University of Latvia, LV-1004 Riga, Latvia; karina.upska@lu.lv (K.U.); \\ linda.dobkevica@lu.lv (L.D.); jorens.kviesis@lu.lv (J.K.); maris.klavins@lu.lv (M.K.) \\ 2 Institute of Chemical Physics, University of Latvia, LV-1004 Riga, Latvia; raimonds.meija@lu.lv \\ 3 Department of Physics, Riga Stradins University, LV-1067 Riga, Latvia \\ * Correspondence: linda.ansone-bertina@lu.lv
}

check for updates

Citation: Ansone-Bertina, L.; Upska, K.; Dobkevica, L.; Kviesis, J.; Meija, R.; Klavins, M. Immobilised Humic Substances as Low-Cost Sorbents for Emerging Contaminants. Appl. Sci. 2021, 11, 3021. https://doi.org/ 10.3390/app11073021

Academic Editor: Bin Gao

Received: 24 February 2021

Accepted: 24 March 2021

Published: 28 March 2021

Publisher's Note: MDPI stays neutral with regard to jurisdictional claims in published maps and institutional affiliations.

Copyright: (c) 2021 by the authors. Licensee MDPI, Basel, Switzerland. This article is an open access article distributed under the terms and conditions of the Creative Commons Attribution (CC BY) license (https:// creativecommons.org/licenses/by/ $4.0 /)$.

\begin{abstract}
Environmental pollution with contaminants of emerging concern (CECs) is a worldwide problem that is receiving increasing attention. Although these substances have been released in the aquatic environment for a long time, wastewater treatment plants are still incapable of removing emerging contaminants completely. Consequently, trace metals, metalloids and pharmaceuticals, as well as surfactant leftovers, are often found in environmental samples. Environmentally friendly and cost-effective sorbents such as humic substances can be used for purification if their sorption properties are increased by immobilization. To our knowledge, immobilized humic substances have not been widely studied as sorbents up to now. In this study, humic substances were immobilized to obtain low-cost sorbents. The chosen methods for characterization of the obtained sorbents showed successful immobilization. Traditional pollutants, such as Cr(III) (a metal), As(V) (a metalloid) and chlorpromazine (a pharmaceutical), were used as representative contaminants. Sorption experiments were conducted using the batch system, and sorption was also studied based on the sorbent dosage, initial concentration of the studied element or substance, solution $\mathrm{pH}$ and sorption time. The results show that all the obtained immobilized humic substances in this study can be used as sorbents to remove contaminants from water. At the same time, from these humic substances, only those immobilized using iron compounds are suitable for the removal of arsenic.
\end{abstract}

Keywords: humic substances; immobilization; contaminants of emerging concern; chromium; arsenic; pharmaceuticals

\section{Introduction}

Nowadays, environmental pollution is a worldwide problem. Various human activities have been producing a wide range of pollutants, including both organic and inorganic substances. Increasing attention has been paid to contaminants of emerging concern (CECs), or emerging contaminants, such as potentially toxic metals, pharmaceuticals and personal care products, surfactants, pesticides, steroid hormones, plasticizers and food additives in aqueous media. At present, there is no standard categorization of CECs. They have been released in the aquatic environment for a long time, but the lack of suitable technology has not allowed us to detect them in the past. Despite the progress of treatment technology, wastewater treatment plants are still not capable of removing emerging contaminants completely. As a result, trace metals, metalloids and pharmaceuticals are often found in environmental samples [1]. Moreover, several studies reported that sewage effluents and industrial waste in some developing countries might be discharged in surface waters without treatment, thus polluting the available water supply [2]. The WHO reported that over one billion people globally lack access to safe drinking water supplies, and taking into account present global consumption patterns, it is predicted that two thirds of the global population may be living in water-stressed conditions by the year 2025 [3]. To improve the 
existing situation, new approaches are still being sought, and the improvement of existing techniques is also crucial.

One of the extensively used groups of chemicals is surfactants. Their physicochemical properties (amphiphilicity, solubility in both polar and nonpolar liquids, ability to form micelles and adsorption on phase boundaries) make them useful in industry and household applications [4]. Due to their cleaning properties, they are used as ingredients in care products (shampoos and body wash) as well as household cleaning products. When entering the environment, surfactants can undergo aerobic and anaerobic degradation [5]. Surfactants can be classified by applying several different criteria (e.g., raw material source, the effect of the environment, possible application and their chemical structure). According to their chemical structure, surfactants can be classified as ionic (anionic, cationic and amphoteric) and nonionic [4].

Heavy metals are a group of inorganic pollutants that are introduced into the environment due to natural processes, as well as anthropogenic activities such as mining, smelting, warfare and military training, military industries, fossil fuel consumption, improper waste disposal, wastewater discharge, agrochemical use and irrigation [6,7]. Toxic or potentially toxic metal ions (e.g., cadmium (Cd), mercury (Hg), nickel (Ni), lead (Pb), vanadium (V) and zinc (Zn)) as well as metalloids (arsenic (As) and selenium (Se)) can accumulate in aquatic environments and soils, thus posing health risks for humans, animals and plants [2]. Elevated concentrations of the previously mentioned elements, as well as effluents caused by both natural processes and anthropogenic activities, are found in surface water and groundwater.

Another essential pollutant group involves organic substances, and increasing attention has been paid to pharmaceuticals in the aquatic environment. These emerging contaminants enter the aquatic environment through various routes, such as the direct discharge of raw and treated wastewater from municipal, household, hospital and industrial wastewater treatment plants; landfill leachate; and surface runoff from urban and agricultural areas, where treated wastewater, sludge or manure waste are used for irrigation and as fertilizers [8]. Currently, more than 200 different pharmaceuticals have been detected in rivers globally, some of them at high concentrations, thus causing toxicity risks for aquatic organisms [8-10]. Petrie et al. [9] concluded that environmental waters in the UK contained approximately 70 pharmaceuticals belonging to different therapeutic classes, such as nonsteroidal anti-inflammatory drugs, $\beta$-blockers, antidepressants and the antiepileptic carbamazepine.

Various technologies for the removal of emerging contaminants from the aqueous system have been developed, including oxidation, coagulation, precipitation, ion exchange and reverse osmosis [11-13]. However, these technologies have significant disadvantages, such as incomplete removal and high operating and maintenance costs, as well as high energy requirements [2]. Therefore, more effective and cost-efficient methods and technologies for the removal of pollutants from the aqueous environment are being sought. Adsorption is considered to be one of the most appropriate methods due to its simplicity and potential for regeneration. It is also economical and easy to set up [13]. Although many different sorbents have been used for the removal of metal, metalloid and organic substances so far, due to unsatisfactory efficiency and the high costs of these sorbents, opportunities are still open for finding new environmentally friendly and cost-effective sorbents. Recently, much attention has been paid to sorbents based on natural materials. There are numerous sorbents that contain unmodified raw materials, such as clay minerals [12] and lignitic humic substances (HSs) [14], and there are also sorbents based on natural materials like wood-based biochar [2], iron-modified peat [15], iron humate [16] and many others. Sorbents based on humic substances could be competitive among such materials, making contributions to reducing pollution.

Humic substances (HSs), the products of degradation reactions of decaying organic matter, are the main component of soil organic matter that affects soil fertility. In addition, HSs are decisive in providing the turnover of organic carbon [17]. HSs are a general category 
of naturally occurring, biogenic, heterogeneous organic substances that can generally be characterized as yellow to black in color and of a high molecular weight. Moreover, the presence of carboxylic and phenolic hydroxyl groups in the HS structure ensures its acidic nature [18]. HSs can be tentatively classified as humic acid (HA), fulvic acid (FA) and humin, depending on their solubility [19]. HSs have many valuable properties, including that they are the main sorbent of organic and inorganic chemicals in soil. There are numerous studies investigating HSs as a sorbent for metals. Klucakova and Pavlikova [14] concluded that the adsorption efficiency of HSs was $80-100 \%$, and the stability of formed metal ion-humic complexes was high for copper and lead, even if it was lower for zinc and cadmium. In recent decades, HSs have been used as a sorbent in HPLC, capillary electrochromatography and solid-phase extraction, and in these applications, they are immobilized prior to use [20].

HSs are mostly used as a native substance, but recently, more attention has been paid to the methods of their chemical modification to improve their physicochemical properties. It is important to investigate different approaches to the modification of HSs, including immobilization, in order to obtain a new, improved material with prospective wide application. Moreover, to better understand the mechanism of sorption, it is also important to characterize the obtained sorbents. Klavins and Eglite [17] found the immobilization of HSs to be promising for investigating their interaction with different substances. The authors pointed out that immobilized HSs could serve as a sorbent for organic and inorganic substances, enabling the study of their interactions [17]. Furthermore, Cihlar et al. [21] studied the hydration and water-holding properties of cross-linked HAs (a formaldehyde cross-linking procedure based on the covalent coupling of aromatic moieties of HSs) to obtain a low-cost material that could be used in agriculture and remediation technology. There have been several attempts to immobilize HAs on silica. Speltini et al. [22] proposed a green and inexpensive method for the immobilization of humic substances by thermally condensing them onto silica in order to obtain a sorbent for glucocorticoids, namely the substances of the steroidal hormone class. Stathi and Deligiannakis [23], studying the uptake of heavy metals $\left(\mathrm{Pb}^{2+}, \mathrm{Cd}^{2+}, \mathrm{Cu}^{2+}, \mathrm{Zn}^{2+}\right.$ and $\left.\mathrm{Mg}^{2+}\right)$ from an aqueous solution, found that an $\mathrm{SiO}_{2}$-immobilized $\mathrm{HA}$ sorbent was effective in metal uptake. One of the most important advantages of immobilized HSs is that they can be separated from solutions more effectively [24].

Humic substances can be isolated, for example, from compost and sludge, as well as the result of processing of biomass waste. Therefore, biomass waste and compost humic substances can be considered as renewable material. Many of the elaborated sorbents are developed without considering economic aspects. Humic substances are low-cost materials and thus humic-based sorbents, and especially when using the suggested approaches, they can also be considered as low-cost sorbents. There are many sorbents which are designed for the removal of heavy metals, but not that many are developed for the removal of emerging pollutants such as pharmaceuticals. This study was aimed at immobilizing humic substances and investigating their properties for potential use as a low-cost sorbent of contaminants of emerging concern (in this case, cations $(\mathrm{Cr}(\mathrm{III}))$, anions $(\mathrm{As}(\mathrm{V}))$ and pharmaceuticals (chlorpromazine)).

\section{Materials and Methods}

\subsection{Immobilization of Humic Substances}

\subsubsection{Immobilization of Humic Substances by Polycondensation}

A total of $20 \mathrm{~g}$ of crushed HSs (Humin Tech GmbH, Germany, Grevenbroich, 95.5\% HA) were dissolved in $100 \mathrm{~mL}$ of formic acid (Merck, Kenilworth, NJ, USA, for synthesis), stirred and heated in a water bath at a $371 \mathrm{~K}$ temperature. Then, $20 \mathrm{~g}$ of phenol or resorcinol was added into the mixture and stirred for $1 \mathrm{~h}$. After that, $10 \mathrm{~g}$ of paraformaldehyde (Sigma-Aldrich, St. Louis, USA, reagent grade) was added in small portions to the resulting solution and heated until polymerization was finished $(6 \mathrm{~h})$. The immobilized HSs were 
crushed and washed with hot deionized water (Milli-Q, St. Louis, USA 7,4 $\mu \mathrm{S} / \mathrm{cm}, 371 \mathrm{~K}$ ). The polymerization product was washed using a Soxlet system with ethanol.

\subsubsection{Immobilization of Humic Substances with Iron Compounds}

A total of $20 \mathrm{~g}$ of crushed HSs (Humin Tech $\mathrm{GmbH}, 95.5 \% \mathrm{HA}$ ) was dissolved in a $500 \mathrm{~mL} 2 \% \mathrm{KOH}$ solution, heated, stirred and left overnight. On the next day, the solution was heated, and $50 \mathrm{~mL}$ of $1 \mathrm{M} \mathrm{FeCl}_{3}$ (Chempur, Piekary Sląskie, Poland, analytically pure) was added until the precipitation was complete, after which it was left overnight again. The resulting product was filtered and washed with deionized water (Milli-Q, 7,4 $\mu \mathrm{S} / \mathrm{cm}$, $293 \mathrm{~K})$.

\subsection{Characterization of Immobilized Humic Substances}

The HSs were characterized in order to better understand their structures, including the content of elements $(\mathrm{C}, \mathrm{H}, \mathrm{N}, \mathrm{O})$ and phenolic and carboxylic groups, and obtain thermogravimetric analysis data. Scanning electron microscopy gave insight into the surface morphology of the HSs after immobilization and thus provided an opportunity to compare the visual differences in the surface morphology of the studied materials before and after immobilization. The BET (Brunauer-Emmett-Teller) method was used to determine one of the most important parameters of the sorbent: the specific surface area.

The elemental analysis (C, H, N and O) was carried out using a model EA-1108 elemental analyzer (Carlo Erba Instruments, Egelsbach, Germany), and the discovered values were normalized with respect to the ash content. The ash content was measured after heating $50 \mathrm{mg}$ of each HS sample at $750{ }^{\circ} \mathrm{C}$ for $8 \mathrm{~h}$.

The carboxylic and phenolic groups of each HS sample were determined using a TitroLine easy automatic titrator (Schott-Geräte GmbH, Mainz, Germany). The well-known Ca acetate method [18], based on the formation of acetic acid, was used for determining the total number of carboxylic groups. For this, $20 \mathrm{mg}$ of the immobilized HSs was weighed into a $100 \mathrm{~mL}$ Erlenmeyer flask, and $10 \mathrm{~mL}$ of a $0.2 \mathrm{~N}$ calcium acetate solution was added under an $\mathrm{N}_{2}$ atmosphere. The samples were potentiometrically titrated to a $\mathrm{pH}$ of 9.0 with $0.1 \mathrm{~N} \mathrm{NaOH}$. To estimate the total acidity, $20 \mathrm{mg}$ of the sample was dispersed in $10 \mathrm{~mL}$ of a $0.1 \mathrm{M} \mathrm{Ba}(\mathrm{OH})_{2}$ solution, which was then shaken overnight under an $\mathrm{N}_{2}$ atmosphere, filtered and washed with water. The filtrate, together with the washing solution, was potentiometrically titrated with $0.1 \mathrm{M} \mathrm{HCl}$ down to a $\mathrm{pH}$ of 8.4 under an $\mathrm{N}_{2}$ flow.

Thermogravimetric analysis (TGA) was performed by weighing a $5 \mathrm{mg}$ sample into a ceramic crucible, which was then analyzed with a TA Instruments-Waters LLC SDT Q600 (New Castle, DE, USA) under an $\mathrm{N}_{2}$ atmosphere at a gas flow rate of $100 \mathrm{~mL} / \mathrm{min}$. The temperature increase was $15^{\circ} \mathrm{C} / \mathrm{min}$, and the samples were heated from room temperature to $105{ }^{\circ} \mathrm{C}$ and kept isothermal for $2 \mathrm{~min}$ to eliminate moisture. The heating was then continued to $900{ }^{\circ} \mathrm{C}$. The weight loss and derivative data were recorded.

Scanning electron microscopy (SEM) was used to determine changes in the surface morphology of a sample after immobilization of the HS. The sample was applied to a double-sided disc made of a carbon-based material that was electrically conductive. The samples were placed in a Hitachi S-4800 scanning electron microscope with a voltage of $3.0 \mathrm{kV}$. Image J was used for data processing.

The surface area of the sorbents was measured using a Quantachrome QUADRASORB SI Kr surface area pore size analyzer with a standard Autosorb degasser. The Langmuir method was used for specific surface area measurements.

\subsection{Sorption Experiments}

Sorption experiments were conducted using the batch system. $\mathrm{Na}_{2} \mathrm{HAsO}_{4} \cdot 7 \mathrm{H}_{2} \mathrm{O}$ (Sigma-Aldrich) and $\mathrm{Cr}\left(\mathrm{NO}_{3}\right)_{3} \cdot 9 \mathrm{H}_{2} \mathrm{O}$ were used for $\mathrm{As}(\mathrm{V})$ and $\mathrm{Cr}(\mathrm{III})$ stock solution preparation, respectively, while chlorpromazine hydrochloride ( $(\geq 98 \%$ (TLC) Sigma-Aldrich) (Figure 1) was used as an exemplar of pharmaceuticals. A chlorpromazine $\mathrm{HCl}$ working standard $(5-550 \mu \mathrm{g} / \mathrm{mL})$ was dissolved in $1 \%$ ammonium acetate. 


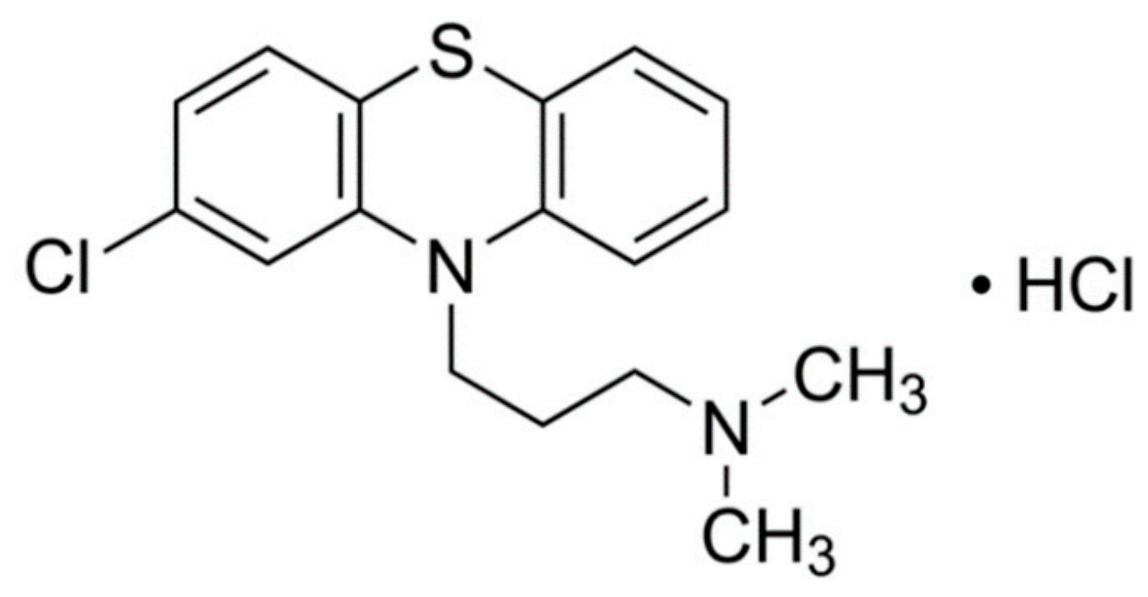

Figure 1. Chlorpromazine hydrochloride.

A total of $50 \mathrm{~mL}$ of an $\mathrm{As}(\mathrm{V}), \mathrm{Cr}(\mathrm{III})$ or chlorpromazine $\mathrm{HCl}$ solution was added in each $100 \mathrm{~mL}$ glass vessel with $0.05 \mathrm{~g}$ or $0.1 \mathrm{~g}$ of sorbent for $\mathrm{As}(\mathrm{V})$. The vessels were shaken for $24 \mathrm{~h}$ at room temperature. The suspensions were then filtered, and arsenic and chromium in the filtrate were analyzed using inductively coupled plasma optical emission spectrometry (ICP-OES), while chlorpromazine was analyzed using ultra-highperformance liquid chromatography. All experiments were performed in duplicate, and the average value was calculated. The sorption capacity of the immobilized HS sorbent was evaluated using the following expression:

$$
q_{e}=\frac{\left(C_{0}-C_{t}\right) * V}{m}
$$

where $q_{e}$ is the mass of the element adsorbed per unit mass of the adsorbent in $\mathrm{mg} / \mathrm{g} ; V$ is the solution volume in $\mathrm{L} ; m$ is the adsorbent mass in $\mathrm{g}$; and $C_{0}$ and $C_{t}$ are the element concentrations in the initial solution and in the solution after adsorption in $\mathrm{mg} / \mathrm{L}$.

The impact of the $\mathrm{pH}$, dosage of the sorbent and contact time were studied. To investigate the $\mathrm{pH}$ impact, either a $0.1 \mathrm{M} \mathrm{HCl}$ or a $0.1 \mathrm{M} \mathrm{NaOH}$ solution was used. In the glass vessels, the necessary amount of $\mathrm{As}(\mathrm{V}), \mathrm{Cr}(\mathrm{III})$ or chlorpromazine $\mathrm{HCl}$ stock solution was added to $0.1 \mathrm{~g}$ of immobilized HSs. The varied $\mathrm{pH}$ solutions were prepared by adding $0.1 \mathrm{M} \mathrm{NaOH}$ or $0.1 \mathrm{M} \mathrm{HCl}$ dropwise to achieve $\mathrm{pH}$ values of 3-10. After that, the reaction mixture was shaken for $24 \mathrm{~h}$ at room temperature and filtered. Finally, the $\mathrm{pH}$ scale was measured. The filtrates were analyzed with ICP-OES or with a chromatograph. The point zero charge (pHpzc) of the immobilized HSs was determined with the method outlined by Fiol and Villaescus [25].

The impact of the sorbent dosage was investigated using different dosages of the immobilized HSs (0.05-1.2 g), while the concentration of the sorbate was kept constant. The kinetics of the sorption process was evaluated in the sorption experiments in the same manner as previously described. The initial $\mathrm{As}(\mathrm{V})$ and $\mathrm{Cr}(\mathrm{III})$ concentrations were $100 \mathrm{mg} / \mathrm{L}$ and $8 \mathrm{mg} / \mathrm{L}$ respectively, and the sorbate concentration in the solution phase was measured after $0.2,0.5,1,2,3,4,5,6,7$ and $24 \mathrm{~h}$.

The concentration of As and $\mathrm{Cr}$ in the solution was determined by inductively coupled plasma optical emission spectrometry (ICP-OES) using a Thermo Scientific iCAP7000 spectrometer. The measurement was carried out using argon gas (AGA, 5.0) at a $7000 \mathrm{~K}$ temperature, $0.5 \mathrm{~L} / \mathrm{min}$ plasma gas flow rate and $1.15 \mathrm{~kW}$ of applied power. The analyses were performed at a wavelength of $189.042 \mathrm{~nm}$ (LOD - limit of detection $=0.02 \mathrm{mg} / \mathrm{L}$, LOQ-limit of quantification $=0.07 \mathrm{mg} / \mathrm{L}$, uncertainty $=3 \%$ ) for arsenic and a wavelength of $267.716 \mathrm{~nm}(\mathrm{LOD}=0.04 \mathrm{mg} / \mathrm{L}, \mathrm{LOQ}=0.12 \mathrm{mg} / \mathrm{L}$, uncertainty $=3 \%)$ for chromium. A standard $1000 \mathrm{mg} / \mathrm{L}$ arsenic solution (atomic spectroscopy standard in $2 \% \mathrm{HNO}_{3}$, Perkin Elmer, Waltham, MA, USA) and a $1000 \mathrm{mg} / \mathrm{L}$ chromium solution (Fisher Scientific, Waltham, MA, USA, high purity reagent) were used to plot the calibration curves. 
Ultra-Performance Liquid Chromatography (UPLC) analysis of chlorpromazine. Chromatographic separation was carried out using Waters Acquity UPLC H-class equipment (Milford, MA, USA) that consisted of an ultra-high-pressure gradient unit (Quaternary Solvent Manager), an autoinjector (FTN), a column oven (CHA) and a fluorescence detector (FLR). Chromatographic data were collected by means of the Waters Empower chromatography software. Chromatography was carried out at $30^{\circ} \mathrm{C}$ using an Acquity UPLC HSS CYANO column $(1.7 \mu \mathrm{m}, 2.1 \times 450 \mathrm{~mm})$. The mobile phase consisted of an acetonitrile and $50 \mathrm{mM} \mathrm{CH}_{3} \mathrm{COONH}_{4}$ solution (9:1 v/v) and had a constant flow rate of $0.50 \mathrm{~mL} / \mathrm{min}$. The total separation time was $3.5 \mathrm{~min}$. The identification and quantification of chlorpromazine were performed using a fluorescence detector at an excitation wavelength of $280 \mathrm{~nm}$ and an emission wavelength of $450 \mathrm{~nm}$.

\section{Statistical Data Processing}

Each experiment was run in triplicate, and a standard deviation was calculated and shown in the appropriate figures.

\section{Results and Discussion}

The HSs were immobilized with phenol, resorcinol and iron compounds. Three different immobilized HS samples were obtained: humic substances immobilized with phenol (HSph), humic substances immobilized with resorcinol (HSrz) and humic substances immobilized with iron compounds (HSFe). The obtained samples were characterized, and their sorption capacities for contaminants of emerging concern (exemplified by cations $(\mathrm{Cr}(\mathrm{III}))$, anions $(\mathrm{As}(\mathrm{V}))$ and pharmaceuticals (chlorpromazine)) were investigated.

\subsection{Characterization of Immobilized Humic Substances}

Characterization of the immobilized HSs allowed for better understanding of their structure, including the elemental $(\mathrm{C}, \mathrm{H}, \mathrm{N}, \mathrm{O})$, phenolic and carboxylic group content and the specific surface area (BET) data. Some characteristics of the sorbents of the immobilized HSs are given in Table 1. Furthermore, the thermogravimetric (TG) data were used to characterize the structure elements of the studied samples. The SEM analysis was used to characterize the surface area of the immobilized HS samples.

Table 1. Characterization of the immobilized humic substances (HSs).

\begin{tabular}{|c|c|c|c|c|c|c|c|c|c|}
\hline \multirow{2}{*}{$\begin{array}{c}\text { Immobilized } \\
\text { Humic } \\
\text { Substances }\end{array}$} & \multicolumn{4}{|c|}{ Elemental Content (wt.\%) } & \multirow{2}{*}{$\begin{array}{l}\text { Phenolic } \\
\text { Groups } \\
\text { (meq/g) }\end{array}$} & \multirow{2}{*}{$\begin{array}{l}\text { Carboxylic } \\
\text { Groups } \\
\text { (meq/g) }\end{array}$} & \multirow{2}{*}{$\begin{array}{c}\text { Total } \\
\text { Acidity } \\
\text { (meq/g) }\end{array}$} & \multirow{2}{*}{$\begin{array}{l}\text { Content } \\
\text { of Fe } \\
\text { (mg/g) }\end{array}$} & \multirow{2}{*}{$\begin{array}{c}\text { Surface } \\
\text { Area } \\
\left(\mathrm{m}^{2} / \mathrm{g}\right)\end{array}$} \\
\hline & $C$ & $\mathbf{H}$ & $\mathbf{N}$ & O & & & & & \\
\hline HSph & 65.92 & 5.15 & 0.47 & 28.46 & 8.8 & 2.2 & 11 & 4.1 & 0.550 \\
\hline HSrz & 61.13 & 4.60 & 0.43 & 33.84 & - & - & - & - & 0.120 \\
\hline HSFe & 41.42 & 3.60 & 0.99 & 53.99 & 3.9 & 1 & 4.9 & 133.3 & 0.035 \\
\hline
\end{tabular}

The elemental content $(\mathrm{C}, \mathrm{H}, \mathrm{N}, \mathrm{O})$ of the immobilized HSs (see Table 1) indicated that the content of carbon was similar in the HS samples that had been immobilized with organic substances (phenol and resorcinol), reaching $65.9 \%$ and $61.1 \%$, respectively, while the carbon content was lower in the HS sample immobilized with iron compounds. The ash content of the immobilized HS samples determined by TG were $9.5 \%, 11.4 \%$ and $11.7 \%$ for HSph, HSrz and HSFe, respectively. The obtained results were as expected and could indicate that the immobilization process had been effective. The iron content of the original HSs was $10.7 \mathrm{mg} / \mathrm{g}$. By comparison, when immobilized by a polycondensation reaction with phenol, the determined iron content in the product was $4.1 \mathrm{mg} / \mathrm{g}$. When immobilizing the HSs with iron compounds, the iron content in the product increased to $133.3 \mathrm{mg} / \mathrm{g}$. The highest surface area was characteristic of the HSs immobilized with phenol, while the Fe-modified sample had the lowest surface area. 
The scanning electron microscope (SEM) images demonstrated the surface morphologies of the immobilized HSs. By comparing the surface morphology of the immobilized HSs with that of raw HS material, differences are observable. More heterogeneous, wrinkled surface areas were characteristic for the HSrz and HSph samples (Figure 2).
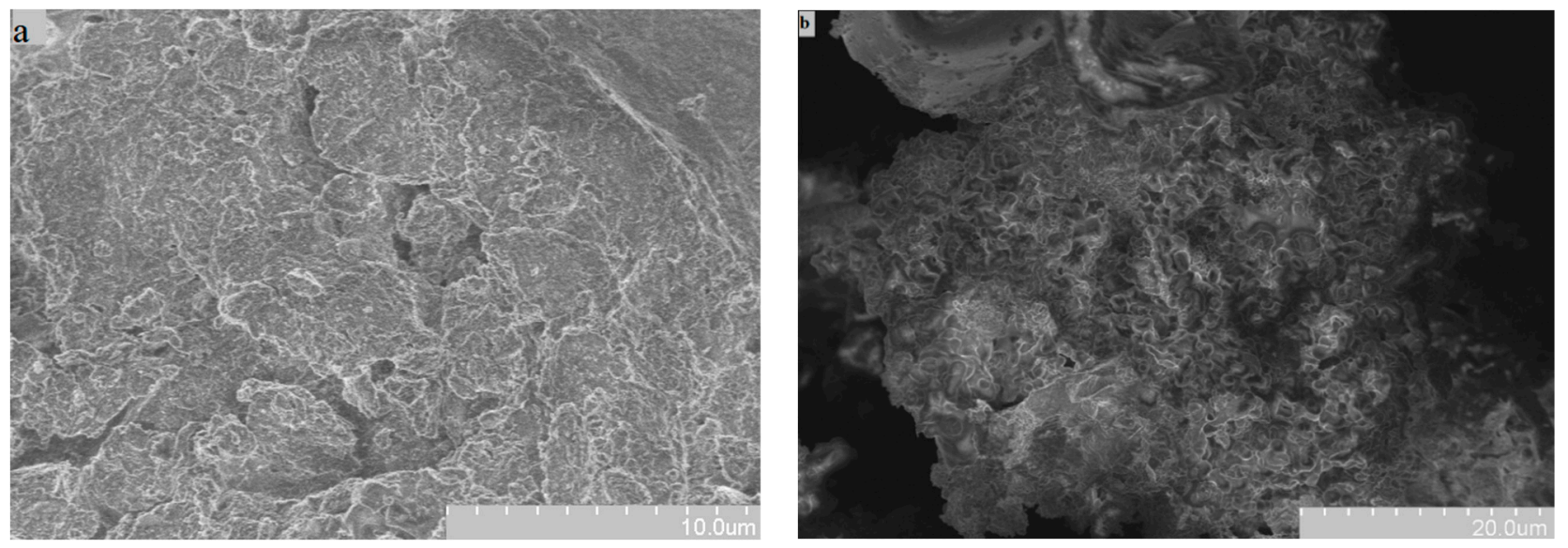

Figure 2. Scanning electron microscope (SEM) images of the immobilized humic substances (a) humic substances immobilized with phenol (HSph) and (b) humic substances immobilized with resorcinol (HSrz).

Thermogravimetric analysis (TGA) could be used to characterize the physicochemical transformations of HS molecules in the pyrolytic degradation process. The weight loss in the heating process (TG, \%) and mass loss rate (DTG - derivative $\mathrm{TG}, \mathrm{m} \% /{ }^{\circ} \mathrm{C}$ ) were determined as part of the study. Decomposition of the carbohydrates and degradation and transformation of the aliphatic structures and HA functional groups (methoxyl, methylene and carboxyl) are typical in the temperature range of $250-340^{\circ} \mathrm{C}$. In turn the carbonyl, alkyl and phenyl groups decompose at $300^{\circ} \mathrm{C}$ [26]. Such decomposition of an immobilized HS sample was well represented by the peak at $250-340{ }^{\circ} \mathrm{C}$ for the HSph and HSFe samples, while an increasing trend of the DTG curve was also observed for the HSrz sample (Figure 3). The HSs immobilized with phenol compounds (HSph) typically had a well-defined peak at a temperature range of $390-530^{\circ} \mathrm{C}$, which corresponded to the degradation of condensed, polyaromatic and polyheterocyclic compounds in the structure of HSs [27]. The less-defined peak was also observed for the HS immobilized with iron compounds (HSFe), and a wide shoulder in the DTG curve could also be observed for the HS immobilized with resorcinol (HSrz) (see Figure 3). 


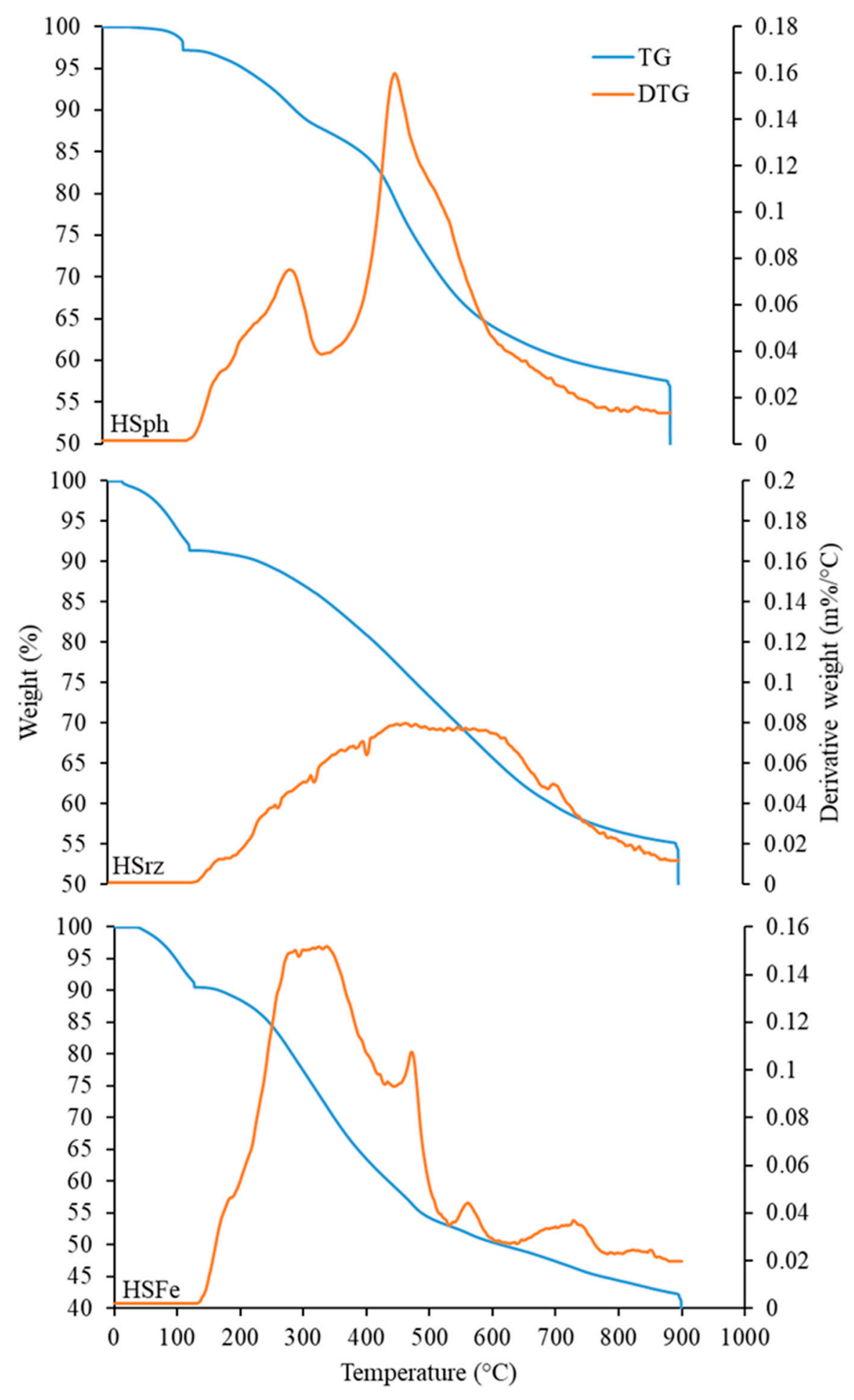

Figure 3. Thermogravimetric (TG) and DTG curves of immobilized humic substance samples (humic substances immobilized by polycondensation with phenol (HSph), resorcinol (HSrz) and iron compounds (HSFe)).

\subsection{Sorption Efficiency}

The impact of the sorbent dosage was investigated using different doses of the immobilized HSs (0.05-1.2 g) while keeping the sorbate concentration and volume constant $(100 \mathrm{mg} / \mathrm{L}, 50 \mathrm{~mL})$. The obtained results indicated that the most appropriate sorbent dosage for As(V) removal was $0.05 \mathrm{~g}$ in the case of using the HSs immobilized with phenol (HSph) or resorcinol (HSrz), while the trend differed when using the HS immobilized with Fe 
compounds (HSFe). The most appropriate dose of the HSFe sorbent for As(V) removal was $0.1 \mathrm{~g}$, because at this sorbent concentration, it was possible to reach the highest sorbed amount of arsenic. Chromium sorption had a similar trend to the arsenic sorption, as all three immobilized HSs showed the highest amount of sorbed chromium at a dose of $0.05 \mathrm{~g}$. The obtained results with the dosage that allowed reaching the highest sorbed amount of the elements in this step were used in further experiments.

For the sorption isotherms, the obtained results of arsenate $(\mathrm{As}(\mathrm{V}))$ sorption for three kinds of immobilized HSs indicated that only the HS that was immobilized with iron compounds could be a prospective sorbent material for the removal of arsenic compounds from polluted waters. The As(V) sorption isotherm using HSFe as a sorbent is shown in Figure 4, where the sorbed amount of arsenic increased and exceeded $16 \mathrm{mg} / \mathrm{g}$ at the initial $\mathrm{As}(\mathrm{V})$ concentration of $750 \mathrm{mg} / \mathrm{L}$.

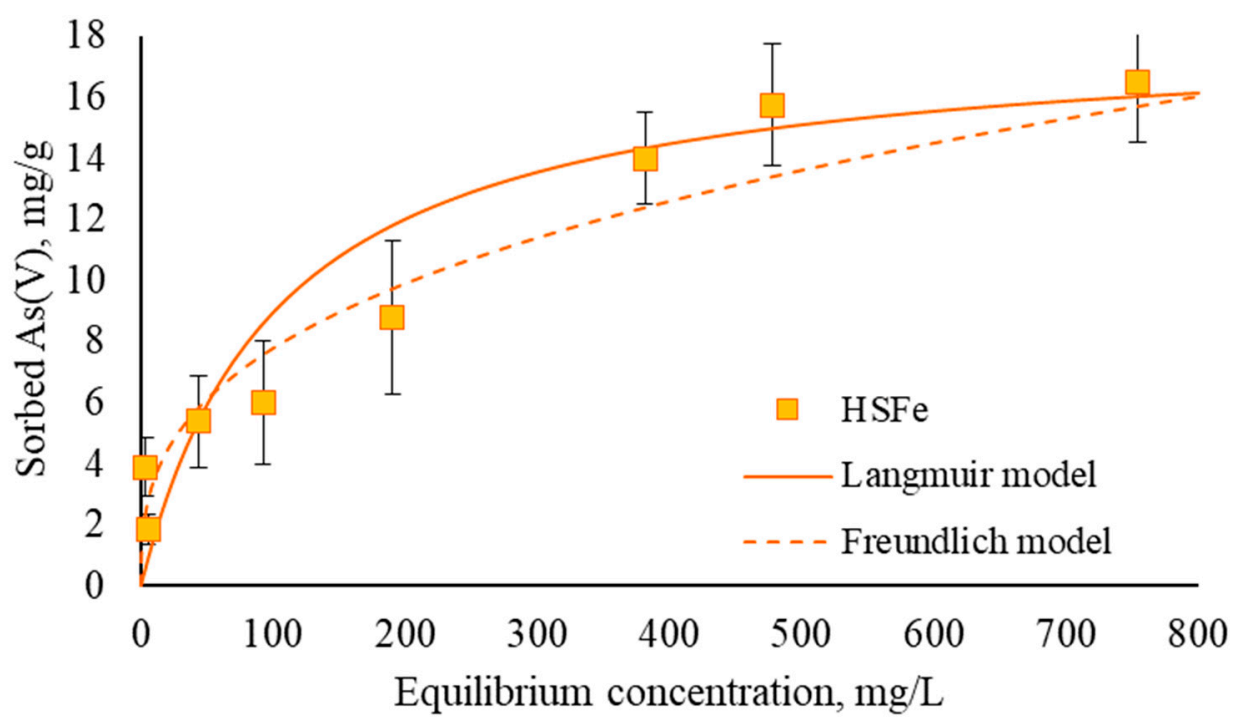

Figure 4. As(V) sorption onto the humic substance sorbent immobilized with iron compounds (HSFe) at a sorption time of $24 \mathrm{~h}$ at room temperature and a $\mathrm{pH}$ of 6 .

Compared with the results of $\mathrm{As}(\mathrm{V})$, the sorbed amount of $\mathrm{Cr}(\mathrm{III})$ onto the HSFe, HSph and HSrz sorbents was considerably lower. Figure 5 shows the sorption isotherms of $\mathrm{Cr}$ (III) when using the HS that was immobilized with iron compounds, resorcinol or phenol as a sorbent. The maximum sorbed amount reached $6 \mathrm{mg} / \mathrm{g}$ at the initial chromium concentration of $60 \mathrm{mg} / \mathrm{L}$ when using the HSs immobilized with Fe compounds and phenol, while the HSs immobilized with resorcinol showed a considerably lower sorption capacity, reaching the highest sorbed amount of $2.45 \mathrm{mg} / \mathrm{g}$ at an initial $\mathrm{Cr}$ (III) concentration of $100 \mathrm{mg} / \mathrm{L}$. The possible mechanism of binding may include the formation of bonds between the metal ions and the hydroxyl groups of the sorbent.

Compared with the sorption capacities of the inorganic substances investigated in this study, the pharmaceutical exemplar yielded even more promising results. Chlorpromazine $\mathrm{HCl}$ sorption was investigated on three kinds of immobilized HSs, and the results indicated that all the studied materials had similar sorption capacities. The highest sorbed chlorpromazine $\mathrm{HCl}$ amount was $55.2 \mathrm{mg} / \mathrm{g}$ for the HSFe sorbent, followed by $46.8 \mathrm{mg} / \mathrm{g}$ for HSrz and a maximum of at least $45.7 \mathrm{mg} / \mathrm{g}$ for HSph (Figure 6). 


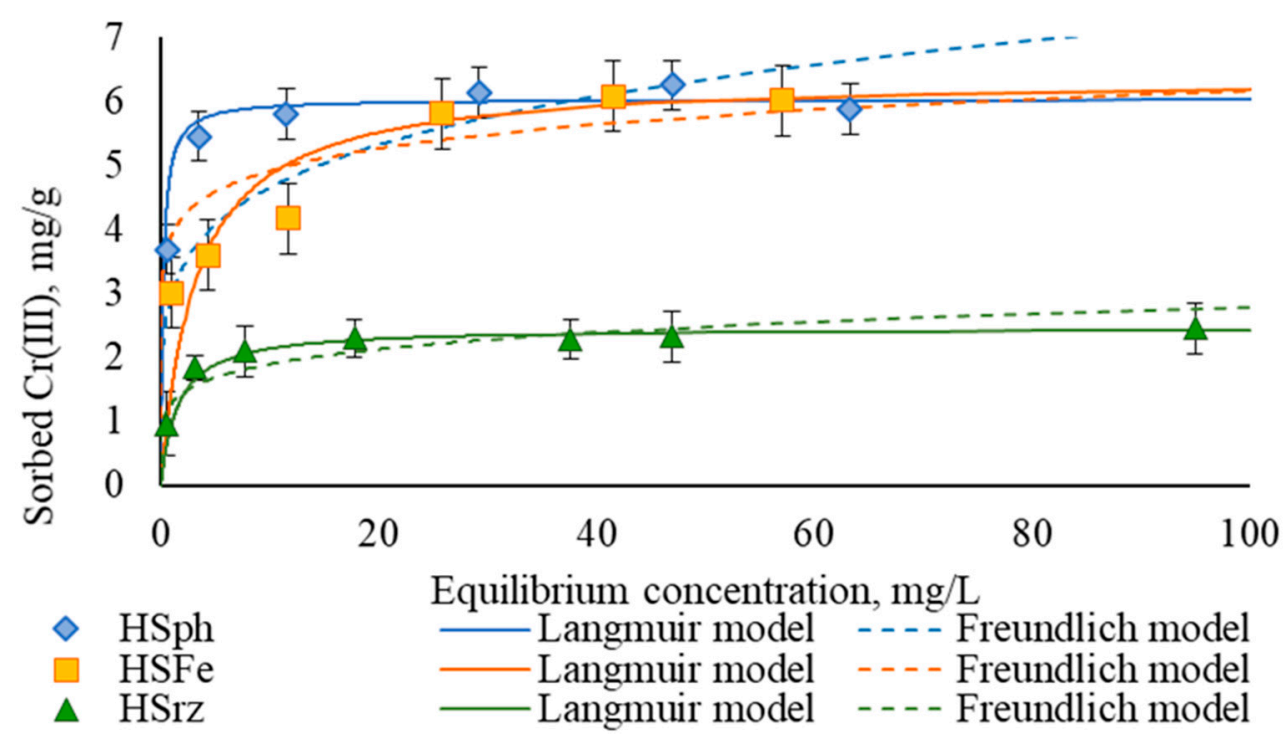

Figure 5. $\mathrm{Cr}(\mathrm{III})$ sorption onto the humic substance sorbent immobilized with iron compounds (HSFe) (in green), phenol (HSph) (in blue) and rezorcinol (HSrz) (in orange), with corresponding Langmuir and Freundlich theoretical sorption models and a sorption time of $24 \mathrm{~h}$ at room temperature with a $\mathrm{pH}$ of 5.5 .

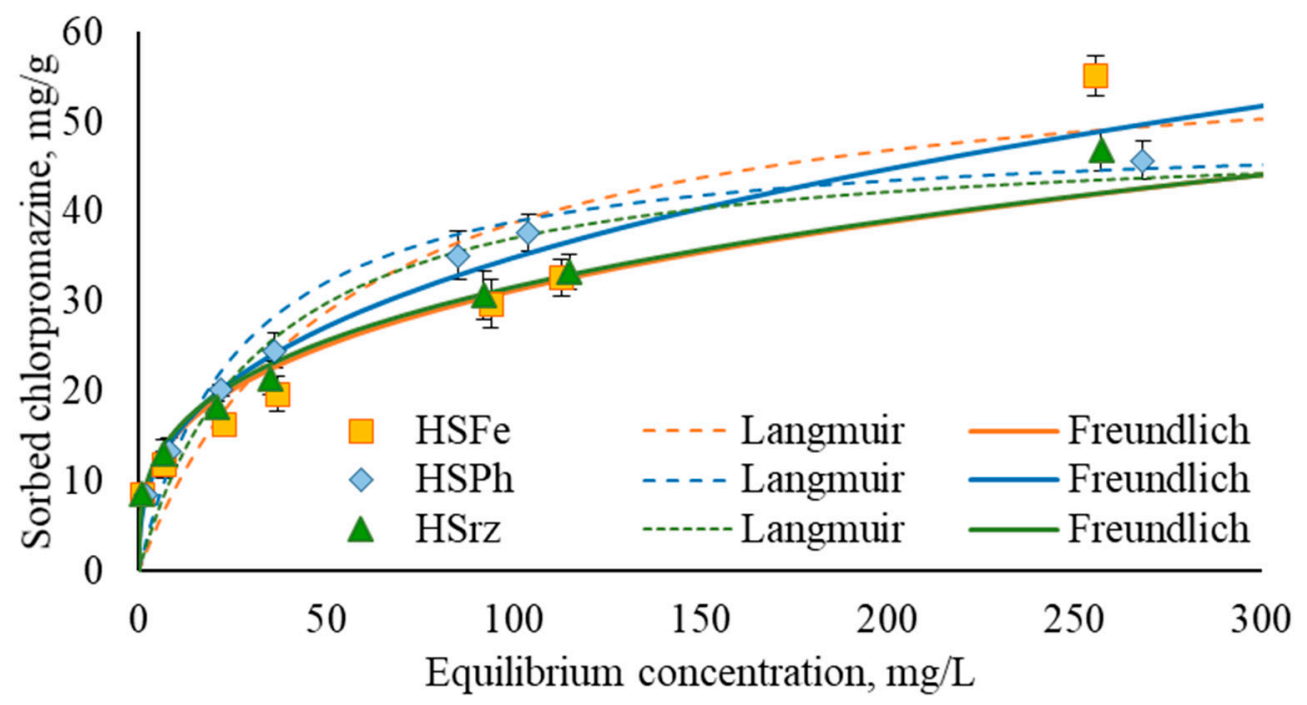

Figure 6. Chlorpromazine $\mathrm{HCl}$ sorption onto immobilized humic substance sorbents, with theoretical Langmuir and Freundlich sorption models having a sorption time of $24 \mathrm{~h}$ at room temperature and a $\mathrm{pH}$ of 6 .

In summation, the immobilized HSs synthesized in this study can be used for removal of metals and metalloids from water. Up to now, immobilized HSs have not been widely studied as sorbents. However, other natural materials modified with iron compounds have been widely studied, and the amounts sorbed by these materials are comparable to those obtained in this study. The maximum sorption capacity of $\mathrm{As}(\mathrm{V})$ was $70.42 \mathrm{mg} / \mathrm{g}$ when using modified (iron (III)-loaded) orange juice industrial residue [28]. In the study by Guo et al. [29], the sorption capacity was $0.0977 \mathrm{mg} / \mathrm{g}$ for sideritecoated sand and $0.0519 \mathrm{mg} / \mathrm{g}$ for hematite-coated sand. Furthermore, the study by Thirunavukkarasu et al. [30] found that the sorption capacities of iron oxide-coated sand and ferrihydrite used for arsenic removal from natural water were 0.0183 and $0.285 \mathrm{mg} / \mathrm{g}$, respectively. Additionally, a comparison can be made with our previous studies, where arsenic sorption on unmodified HSs was low and did not exceed $1 \mathrm{mg} / \mathrm{g}$, while the sorption capacity of the best sorbent (Fe-modified peat) was $15 \mathrm{mg} / \mathrm{g}$ [31]. 
The data of sorption experiments are often compared with theoretical sorption models, such as the Langmuir, Freundlich, Dubinin-Radushkevich and Redlich-Peterson models, among others. In this study, the obtained results were compared with the Langmuir and Freundlich theoretical models. To determine the appropriate isotherm, the linear forms of equations are often used, and linearization is possible in many different types. For example, four different types are possible for the Langmuir equation. In any case, the Langmuir equation (Equation (2)) is the most popular and most appropriate for the assessment of experimental data, and it is as follows:

$$
\frac{C_{e}}{q_{e}}=\frac{1}{q_{m} K_{a}}+\frac{C_{e}}{q_{m}}
$$

where $C_{e}$ is the equilibrium concentration in $\mathrm{mg} / \mathrm{L} ; q_{e}$ is the amount of substance sorbed onto the solid phase in $\mathrm{mg} / \mathrm{g}$; and $q_{m}$ and $K_{a}$ are the Langmuir constants related to the sorption capacity and sorption energy, respectively. In addition, $q_{m}$ is $q_{e}$ for a complete monolayer $(\mathrm{mg} / \mathrm{g})$, and $K_{a}$ is the sorption equilibrium constant $(\mathrm{L} / \mathrm{mg})[32,33]$. Another frequently used sorption isotherm model is the Freundlich model. Its linearized form is shown in Equation (3):

$$
\log q_{e}=\frac{1}{n} \log C_{e}+\log K
$$

where $k$ and $n$ are the Freundlich constants that correspond to the adsorption capacity and adsorption intensity, respectively. The Freundlich model assumes that the sorbent surface is heterogeneous and the sorption sites have diverse energies.

Based on the correlation coefficient, the sorption of arsenic using the HSFe sorbent fit better into the Langmuir sorption isotherm model $\left(R^{2}=0.91\right)$. Nevertheless, the correlation coefficient values were close $\left(R^{2}\right.$ of 0.80 for the Freundlich model), confirming that the experimentally obtained sorption data corresponded to both theoretical isotherm models. It was not even possible to maintain that one of the models was predominant. A similar trend was observed in the sorption results for chromium. The correlation coefficient values were close ( $\mathrm{R}^{2}$ for HSph, HSFe and HSrz were 0.82, 0.95 and 0.82 , respectively, for the Freundlich model and 0.998, 0.999 and 0.992 for the Langmuir model), leading to the conclusion that the experimentally obtained data on $\mathrm{Cr}(\mathrm{III})$ sorption when using the HSFe sorbent corresponded to both theoretical isotherm models.

The effect of the $\mathrm{pH}$ was one of the most important factors that influenced the sorption process. It may affect the chemical form of the investigated element or substance in the solution, as well as the surface properties of the sorbents. The pHpzc was 3.50 for the HSph sorbent and 4.50 for the HSFe sorbent. The obtained pHpzc values indicate that the sorbent surface was positively charged at a $\mathrm{pH}<\mathrm{pHpzc}$ and negatively charged at a $\mathrm{pH}>\mathrm{pHpzc}$. The $\mathrm{pH}$ range of 3-8 was chosen to represent as similar conditions as possible to those in the environment. Inorganic arsenate species are negatively charged in the studied $\mathrm{pH}$ range, and the stable species of $\mathrm{As}(\mathrm{V})$ at the proper $\mathrm{pH}$ range are $\mathrm{H}_{2} \mathrm{AsO}_{4}{ }^{-}(\mathrm{pH} 2-7)$ and $\mathrm{HAsO}_{4}{ }^{2-}$ ( $\left.\mathrm{pH} 7-12\right)$ [34].

Acidic media ( $\mathrm{pH} 3-5)$ are most favourable for the removal of As(V) using HSs immobilized with Fe compounds. The sorbed amount of $\mathrm{As}(\mathrm{V})$ was more than $15 \mathrm{mg} / \mathrm{g}$ (see Figure 7). At the $\mathrm{pH}$ range of 5-7, the sorbed amount of As(V) decreased from $12 \mathrm{mg} / \mathrm{g}$ to $2.4 \mathrm{mg} / \mathrm{g}$. The arsenic species were negatively charged at the studied $\mathrm{pH}$ range. According to the determined pHpzc values, the sorbent surface was positively charged at a $\mathrm{pH}$ range of 3-4.5, the interaction between negatively charged species and the positively charged surface area were favorable, and the sorbed amount was relatively high, while at a $\mathrm{pH}>4.5$, the negatively charged species did not interact, and the sorption capacity of the sorbent decreased. 


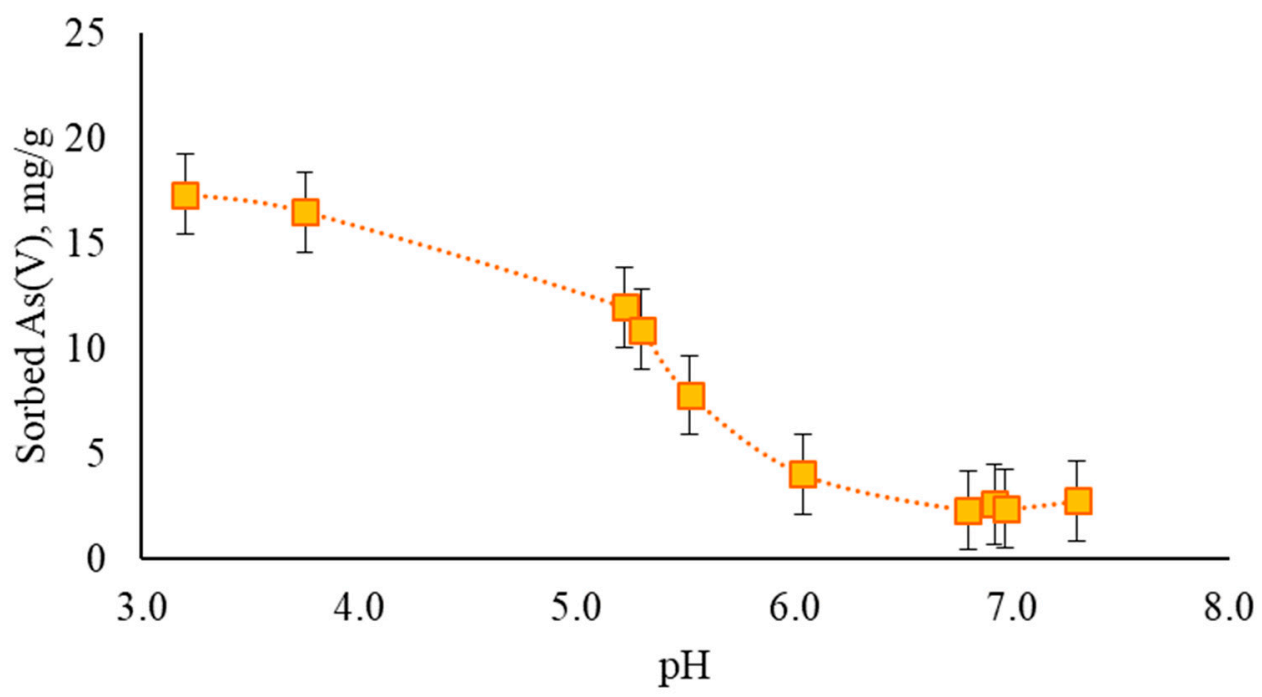

Figure 7. The effect of the $\mathrm{pH}$ on the sorption of $\mathrm{As}(\mathrm{V})$ onto the humic substance sorbent immobilized with iron compounds (HSFe), with a sorption time of $24 \mathrm{~h}$ at room temperature and an initial As(V) concentration of $100 \mathrm{mg} / \mathrm{L}$.

The $\mathrm{Cr}(\mathrm{III})$ ion sorption was negligible in acidic media $(\mathrm{pH} 3)$ but increased at a $\mathrm{pH}>3.5$ (see Figure 8). At this $\mathrm{pH}$ level, the predominant chromium species in the solution were $\mathrm{Cr}_{2}(\mathrm{OH})_{2}{ }^{4+}$ and $\mathrm{Cr}(\mathrm{OH})^{2+}$ (see Figure 9), while with a $\mathrm{pH}$ value increased to 5.5, the predominant species were $\mathrm{Cr}_{3}(\mathrm{OH})_{4}{ }^{5+}$ and $\mathrm{Cr}(\mathrm{OH})_{2}{ }^{+}$. All of the positively charged chromium species may react with the negatively charged sorbent surface (the HSph surface was negatively charged at a $\mathrm{pH}>3.5$ ). The obtained results indicated that a $\mathrm{pH}$ of 5.5 was more favorable for sorption, with $\mathrm{Cr}_{3}(\mathrm{OH})_{4}{ }^{5+}$ as the predominant form. Experiments were not performed at higher $\mathrm{pH}$ values due to the formation of insoluble $\mathrm{Cr}(\mathrm{OH})_{3}$ at a $\mathrm{pH}>6$.

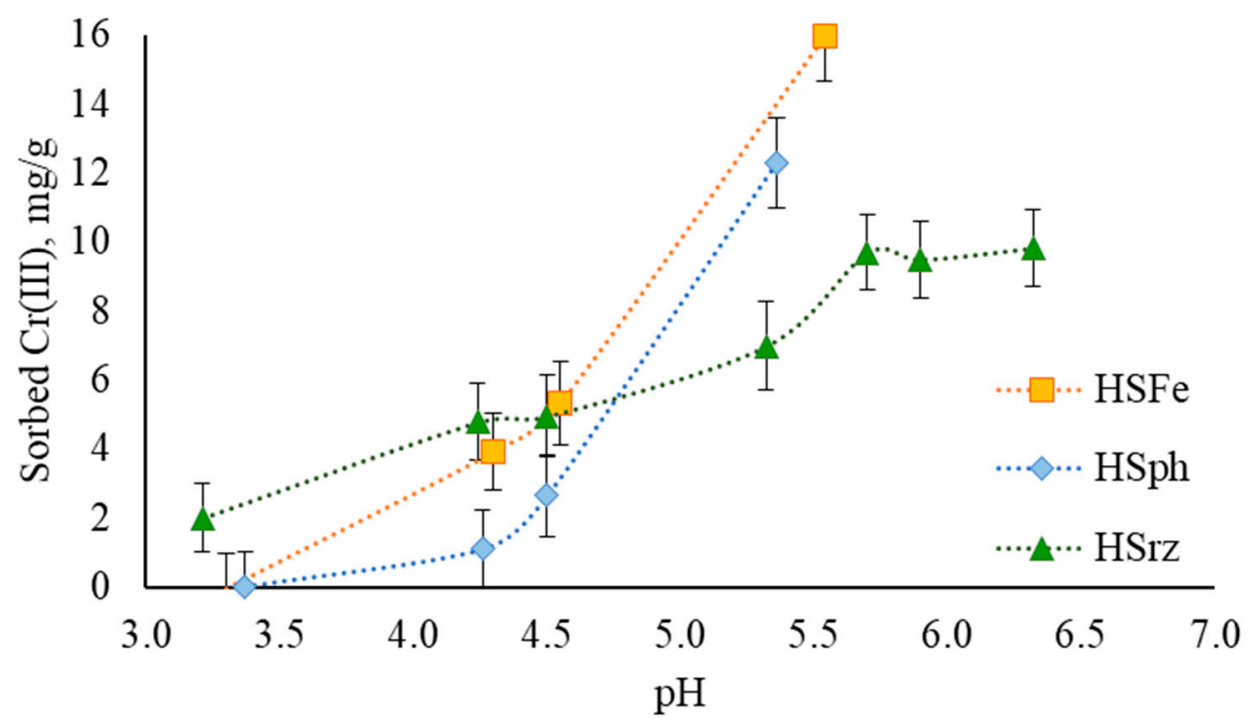

Figure 8. The effect of $\mathrm{pH}$ on the sorption of $\mathrm{Cr}(\mathrm{III})$ onto the humic substance sorbent immobilized with iron compounds (HSFe), phenol (HSph) and resorcinol (HSrz), with a sorption time of $24 \mathrm{~h}$ at room temperature with an initial Cr(III) concentration of $45 \mathrm{mg} / \mathrm{L}$. 


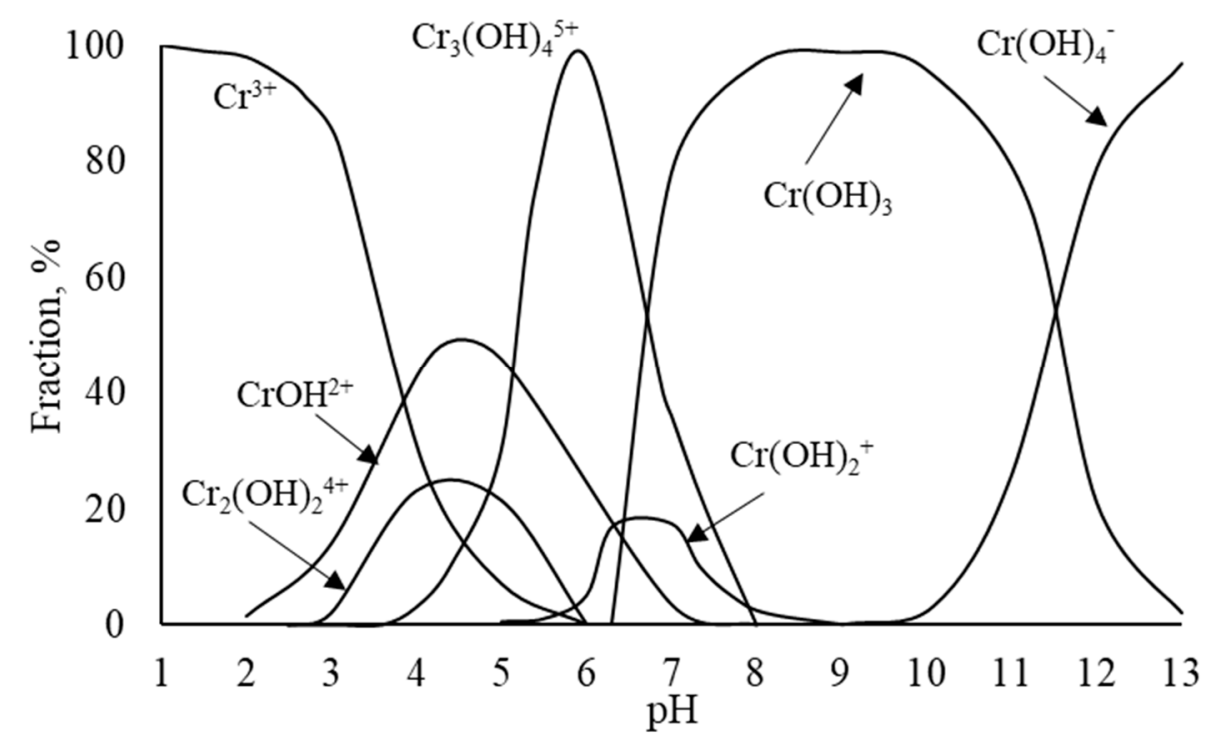

Figure 9. Cr(III) speciation forms, prepared using Visual Minteq 3.1 [35].

The sorbents used for sorbing chlorpromazine in this study showed variability with respect to the sorption capacity, depending on the $\mathrm{pH}$. At the $\mathrm{pH}$ range of 5-9, chlorpromazine mainly occurred in the cationic form [36]. The obtained results (Figure 10) indicate that the amount of chlorpromazine sorbed onto HSph slightly increased in the $\mathrm{pH}$ range of 3-5.5 and did not significantly increase in a more basic environment. Similarly, the HSFe and HSrz sorbents appeared to be more suitable for the removal of chlorpromazine from aqueous solutions under neutral or basic conditions. A relatively rapid increase in the amount of sorbed chlorpromazine (14.6-31 mg/g) was observed with the use of the HSFe sorbent in the $\mathrm{pH}$ range of 3-6, while HSrz had a constant sorbed amount at a $\mathrm{pH}$ of 3-5.5, and the sorbed amount increased at $\mathrm{pH}$ values above 5.5.

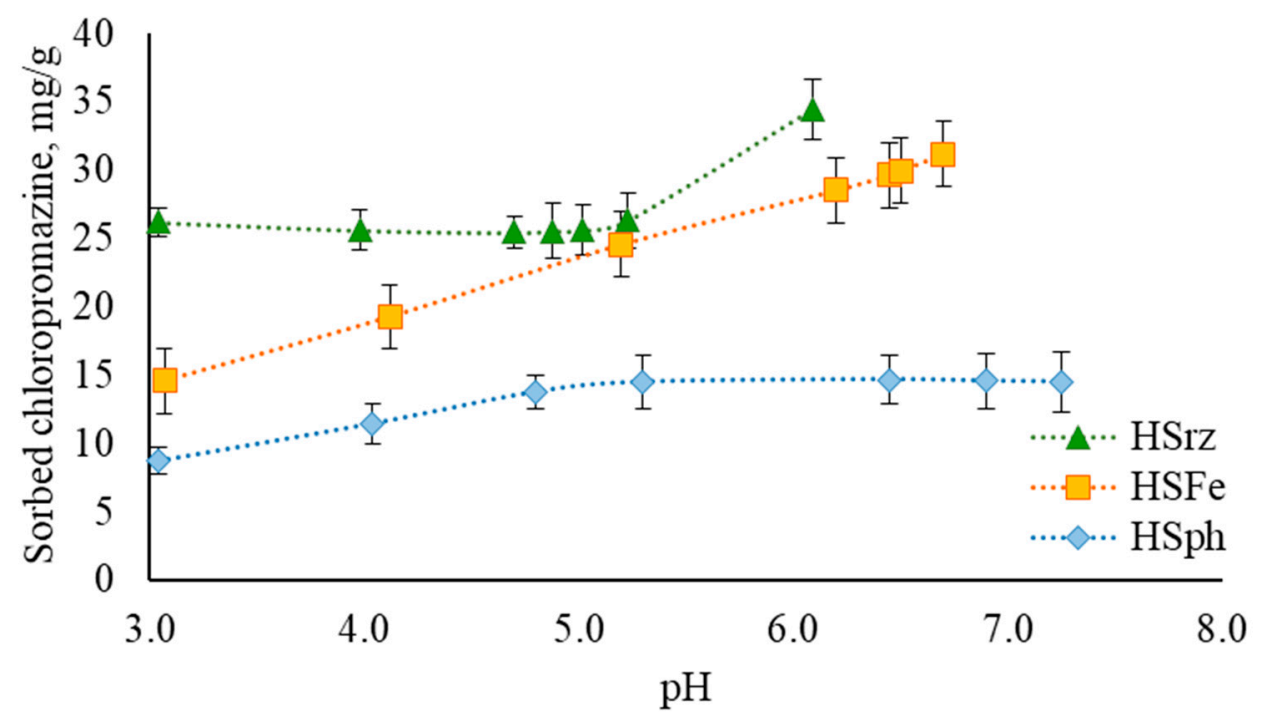

Figure 10. The effect of the $\mathrm{pH}$ level on the sorption of chlorpromazine $\mathrm{HCl}$ onto immobilized humic substance sorbents (HSrz, HSph and HSFe), with a sorption time of $24 \mathrm{~h}$ at room temperature with an initial chlorpromazine $\mathrm{HCl}$ concentration of $80 \mathrm{mg} / \mathrm{L}$.

Concerning the effect of the contact time, according to the sorption kinetics study results (Figure 11), the rate of chromium sorption was very high at the beginning of the contact time. Most of the $\mathrm{Cr}$ (III) was sorbed within the first $2 \mathrm{~h}$. The sorbed amount reached 1.9, 2.7 and $3.9 \mathrm{mg} / \mathrm{g}$ with the use of HSrz, HSFe and HSph sorbents, respectively, 
at the initial concentration of $8 \mathrm{mg} / \mathrm{L}$ with $0.1 \mathrm{~g}$ of immobilized HSs. After that, the $\mathrm{Cr}$ (III) sorption rate gradually reduced, and the maximum sorption capacity was reached. During the first $2 \mathrm{~h}$, the sorption capacity increased rapidly, which could have been related to the availability of sorption sites on the sorbent surface. However, when the sorbent surface became saturated with sorbate molecules, the sorption rate tended to decrease.

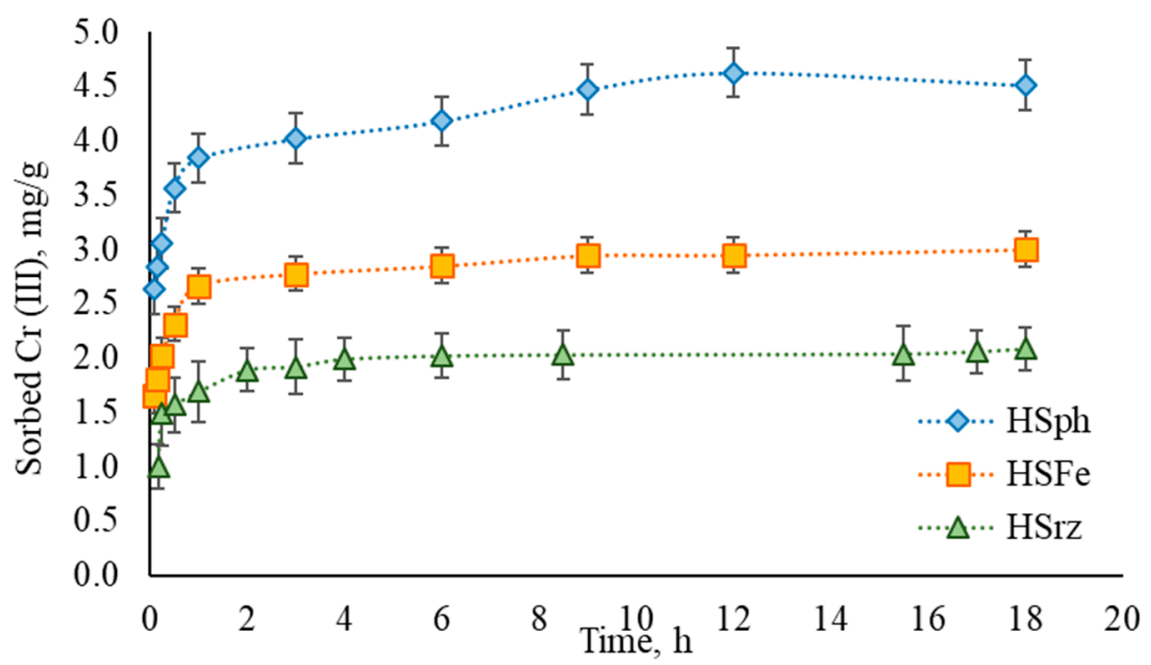

Figure 11. The effect of the contact time on $\mathrm{Cr}(\mathrm{III})$ sorption onto immobilized humic substance sorbents (HSph and HSFe), with an initial Cr(III) concentration of $8 \mathrm{mg} / \mathrm{L}$.

The sorption of $\mathrm{As}(\mathrm{V})$ occurred slower on the HSs immobilized with Fe compounds (HSFe), in contrast to $\mathrm{Cr}$ (III). The amount of sorbed arsenic increased slightly from $2 \mathrm{mg} / \mathrm{g}$ after $2 \mathrm{~h}$ of sorption and reached $4 \mathrm{mg} / \mathrm{g}$ after $24 \mathrm{~h}$ at an initial $\mathrm{As}(\mathrm{V})$ concentration of $100 \mathrm{mg} / \mathrm{L}$. In this case, the sorption isotherm had a relatively slow growing trend. Thus, a longer time period was required to remove arsenic from polluted areas in comparison with Cr (III).

The sorption of chlorpromazine $\mathrm{HCl}$ onto $\mathrm{HSph}$ and $\mathrm{HSrz}$ occurred more rapidly in the first hour (Figure 12). After that, the amount of sorbed chlorpromazine increased over the next $24 \mathrm{~h}$, but at a slower rate. In contrast to this, the HSs immobilized with $\mathrm{Fe}$ compounds (HSFe) reached the highest sorbed amount of chlorpromazine $\mathrm{HCl}$ over a longer period of time.

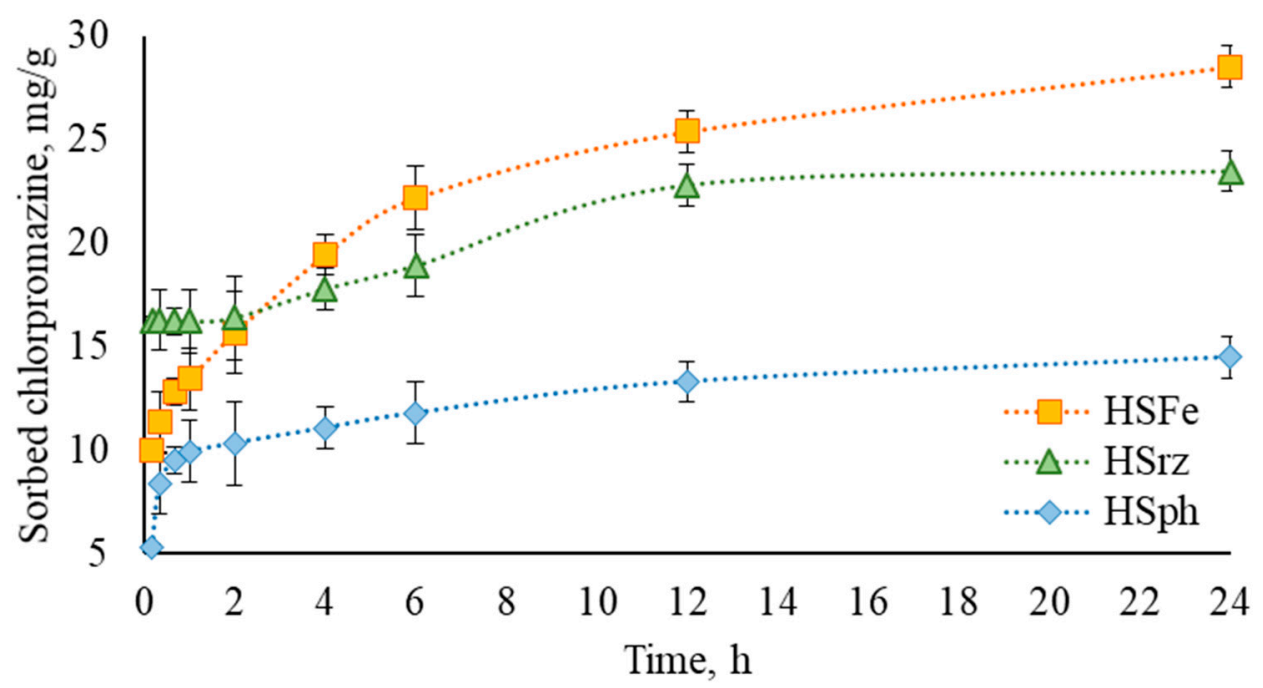

Figure 12. The effect of the contact time on chlorpromazine $\mathrm{HCl}$ sorption onto immobilized humic substance sorbents (HSrz, $\mathrm{HSph}, \mathrm{HSFe}$ ), with an initial chlorpromazine $\mathrm{HCl}$ concentration of $80 \mathrm{mg} / \mathrm{L}$. 
Kinetic models are often used to characterize the sorption process. In order to explore the mechanisms of sorption and potential rate-controlling steps, we applied chemical reaction processes and the mass transport pseudo first-order and pseudo second-order models to evaluate the experimental data. An appropriate sorption model was determined by comparing the determination coefficients in the pseudo first- and pseudo secondorder equations.

A pseudo first-order reaction is expressed as follows:

$$
\ln \left(q_{e}-q_{t}\right)=\ln q_{e}-k_{1} t
$$

where $q_{e}$ is the sorbate sorbed at equilibrium $(\mathrm{g} / \mathrm{g}), q_{t}$ is the sorbate sorbed at time $t(\mathrm{~g} / \mathrm{g}), t$ is the time $(\mathrm{min})$ and $k_{1}$ is the reaction rate constant $(1 / \mathrm{min})$. A pseudo first-order reaction rate constant can be determined from the slope of the $\ln \left(q_{e}-q_{t}\right)$ vs. $t$ graph.

A pseudo second-order reaction is expressed as follows:

$$
\frac{t}{q_{t}}=\frac{1}{k_{2} q_{e}^{2}}+\frac{1}{q_{e}}
$$

where $k_{2}$ is the reaction rate constant $(\mathrm{g} / \mathrm{g} \mathrm{min})$. A pseudo second-order reaction rate constant $\left(k_{2}\right)$ can be determined from the slope of the $t / q_{t}$ vs. $t$ graph [37].

The linear regression coefficient of determination $\left(\mathrm{R}^{2}\right)$ and parameters of the pseudo first- and pseudo second-order reactions were calculated. The experimental data showed that the pseudo second-order kinetic model could explain the process of $\mathrm{As}(\mathrm{V}), \mathrm{Cr}(\mathrm{III})$ and chlorpromazine $\mathrm{HCl}$ sorption on immobilized $\mathrm{HS}$ sorbents better than the pseudo first-order model, since the correlation coefficient $\mathrm{R}^{2}$ was 0.96 for As(V) on HSFe, 0.9998, 0.9998 and 0.999 for $\mathrm{Cr}(\mathrm{III})$ on HsFe, HSrz and HSph, respectively, and 0.996, 0.996 and 0.993 for chlorpromazine $\mathrm{HCl}$ when using the HSrz, HSph and HsFe sorbents, respectively. The experimental values for $\mathrm{Cr}$ (III) qe exp were consistent with the estimated qeq values of $4.51 \mathrm{mg} / \mathrm{g}, 3.0 \mathrm{mg} / \mathrm{g}$ and $2.09 \mathrm{mg} / \mathrm{g}$ (HSph, HSFe and HSrz, respectively). Moreover, the estimated $\mathrm{q}_{\mathrm{eq}}$ values for chlorpromazine $\mathrm{HCl}$ were $29.2 \mathrm{mg} / \mathrm{g}, 23.8 \mathrm{mg} / \mathrm{g}$ and $14.6 \mathrm{mg} / \mathrm{g}$ (HSFe, HSrz and HSph, respectively). These values were calculated with the pseudo second-order equation. Finally, the estimated reaction rate constant $\mathrm{k}_{2}$ was $0.0011 \mathrm{mg} / \mathrm{g}$ min for HSrz, $0.0016 \mathrm{mg} / \mathrm{g}$ min for HSph and $0.0004 \mathrm{mg} / \mathrm{g}$ min for HSFe. The Cr(III) sorption results gave the estimated reaction rate constant $\mathrm{k}_{2}$ of $0.18 \mathrm{mg} / \mathrm{g}$ min for HSrz, $0.40 \mathrm{mg} / \mathrm{g}$ min for HSph and $0.31 \mathrm{mg} / \mathrm{g}$ min for HSFe, while the HSFe estimated reaction rate constant in sorbing $\mathrm{As}(\mathrm{V})$ was $0.025 \mathrm{mg} / \mathrm{g}$ min.

\section{Conclusions}

In this study, humic substances were immobilized, and three kinds of new materials were obtained: humic substances immobilized with (1) phenol (HSPh), (2) resorcinol (HSrz) and (3) iron compounds (HSFe). The characterizations of the obtained materials indicated that the immobilization was successful.

The results showed that all of the immobilized HSs obtained could be used as sorbents to remove emerging contaminants (such as metals ( $\mathrm{Cr}$ (III)) and pharmaceuticals) from water. At the same time, only the HSs immobilized using iron compounds were suitable for the purification of water from arsenic. To our knowledge, immobilized HSs have not been widely studied as sorbents up to now. Compared to the iron-modified natural materials described in other studies, the sorbents of immobilized HSs synthesized in this study showed similar pollutant sorption capacities [28-31]. The synthesized sorbents of HSs immobilized with resorcinol, phenol and iron compounds showed promising results for the sorption of chlorpromazine $\mathrm{HCl}$. We believe that these sorbents have potential for use in wastewater treatment from pharmaceuticals.

The capacity of the immobilized HS sorbents to sorb As(V), $\mathrm{Cr}(\mathrm{III})$ and chlorpromazine was affected by the solution's $\mathrm{pH}$ value. Neutral and basic environments are appropriate 
for the removal of $\mathrm{Cr}$ (III) and chlorpromazine, while the highest sorbed amount of arsenates was observed in an acidic environment using the HSFe sorbent.

The kinetic experiment results indicated that the process of sorbing $\mathrm{Cr}$ was rather fast, reaching the maximum sorbed amount within the first two hours and afterward becoming steady, while the removal of arsenic using the HSs immobilized with Fe compounds was slower. The sorption rate of chlorpromazine $\mathrm{HCl}$ onto $\mathrm{HSph}$ and $\mathrm{HSrz}$ ias very high during the first hour but increased at a slower rate starting from the second hour and up to $24 \mathrm{~h}$. All of the experimental data corresponded to the pseudo second-order reaction model.

Author Contributions: Conceptualization, M.K.; methodology, K.U., L.D., L.A.-B., J.K. and R.M.; software, J.K.; validation, L.D., K.U. and L.A.-B.; formal analysis, M.K.; investigation, K.U. and L.A.-B.; resources, L.D.; data curation, L.A.-B. and M.K.; writing-original draft preparation, L.A.B.; writing-review and editing, M.K. and L.D.; visualization, L.A.-B.; supervision, M.K.; project administration, L.D.; funding acquisition, M.K. All authors have read and agreed to the published version of the manuscript.

Funding: This research was supported by the Latvian Council of Science, Fundamental and Applied Research Project No. lzp-2018/1-0009 "Properties and structure of peat humic substances and possibilities of their modification".

Institutional Review Board Statement: Not applicable.

Informed Consent Statement: Not applicable.

Data Availability Statement: Not applicable.

Conflicts of Interest: The authors declare no conflict of interest. The funders had no role in the design of the study; in the collection, analyses, or interpretation of data; in the writing of the manuscript, or in the decision to publish the results.

\section{References}

1. Krzeminski, P.; Tomei, M.C.; Karaolia, P.; Langenhoff, A.; Almeida, C.M.R.; Felis, E.; Gritten, F.; Andersen, H.R.; Fernandes, T.; Manaia, C.M.; et al. Performance of secondary wastewater treatment methods for the removal of contaminants of emerging concern implicated in crop uptake and antibiotic resistance spread: A review. Sci. Total Environ. 2019, 648, 1052-1081. [CrossRef] [PubMed]

2. Shaheen, S.M.; Khan Niazi, N.; Hassan, N.E.E.; Bibi, I.; Wang, H.; Tsang, D.C.W.; Sik, O.Y.; Bolan, N.; Rinklebe, J. Wood-based biochar for the removal of potentially toxic elements in water and wastewater: A critical review. Int. Mater. Rev. 2018, 216-247. [CrossRef]

3. WHO. Water, Health and Ecosystems. 2020. Available online: https://www.who.int/heli/risks/water/water/en/ (accessed on 2 August 2020).

4. Olkowska, E.; Polkowska, Z.; Namiesnik, J. Analytics of surfactants in the environment: Problems and Challenges. Chem. Rev. 2011, 1115667-1115700. [CrossRef]

5. Jardak, K.; Drogui, P.; Daghrir, R. Surfactants in aquatic and terrestrial environment: Occurrence, behavior, and treatment processes. Environ. Sci. Pollut. Res. 2016, 23, 3195-3216. [CrossRef] [PubMed]

6. Liu, L.; Li, W.; Song, W.; Guo, M. Remediation techniques for heavy metal—Contaminated soils: Principles and applicability. Sci. Total Environ. 2018, 633, 206-219. [CrossRef]

7. Ramanayaka, S.; Tsang, D.C.W.; Hou, D.; Sik, O.Y.; Vithanage, M. Green synthesis of graphitic nanobiochar for the removal of emerging contaminants in aqueous media. Sci. Total Environ. 2020, 706, 135725. [CrossRef] [PubMed]

8. Tran, N.H.; Reinhard, M.; Gin, K.Y.-H. Occurrence and fate of emerging contaminants in municipal wastewater treatment plants from different geographical regions-A review. Water Res. 2018, 133, 182-207. [CrossRef] [PubMed]

9. Petrie, B.; Barden, R.; Kasprzyk-Hordern, B. A review on emerging contaminants in wastewaters and the environment: Current knowledge, understudied areas and recommendations for future monitoring. Water Res. 2015, 72, 3-27. [CrossRef]

10. Reichert, F.J.; Souza, D.M.; Martins, A.F. Antipsychotic drugs in hospital wastewater and a preliminary risk assessment. Ecotoxicol. Environ. Saf. 2019, 170, 559-567. [CrossRef]

11. Parga, J.R.; Vazquez, V.; Moreno, H. Thermodynamic studies of the arsenic adsorption on iron species generated by electrocoagulation. J. Metall. 2009. [CrossRef]

12. $\mathrm{Xi}, \mathrm{J} . ; \mathrm{He}, \mathrm{M}$.; Lin, C. Adsorption of antimony(V) on kaolinite as a function of $\mathrm{pH}$, ionic strength and humic acid. Environ. Earth Sci. 2010, 60, 715-722. [CrossRef]

13. Uluozlu, O.D.; Sari, A.; Tuzen, M. Biosorption of antimony from aqueous solution by lichen (Physcia tribacia) biomass. Chem. Eng. J. 2010, 163, 382-388. [CrossRef] 
14. Klucakova, M.; Pavlikova, M. Lignitic humic acids as environmentally-friendly adsorbent for heavy metals. J. Chem. (Hindawi) 2017. [CrossRef]

15. Ansone, L.; Klavins, M.; Jankevica, M.; Viksna, A. Biomass sorbents for metalloid removal. Adsorption 2014, 20, 275-286. [CrossRef]

16. Janos, P. Sorption of basic dyes onto iron humate. Environ. Sci. Technol. 2003, 37, 5792-5798. [CrossRef]

17. Klavins, M.; Eglite, L. Immobilisation of humic substances. Colloids Surf. A Physicochem. Eng. Asp. 2002, 203, 47-54. [CrossRef]

18. Tan, K.H. Soil Sampling, Preparation, and Analysis, 2nd ed.; Taylor \& Francis: New York, NY, USA, 2005.

19. Stevenson, F.J. Humus Chemistry: Genesis, Composition, Reactions, 2nd ed.; Wiley: New York, NY, USA, 1994.

20. Erny, G.L.; Goncalves, B.M.; Esteves, V.I. Immobilised humic substances and immobilised aggregates of humic substances as sorbent for solid phase extraction. J. Chromatogr. A 2013, 1306, 104-108. [CrossRef]

21. Cihlar, Z.; Vojtova, L.; Conte, P.; Nasir, S.; Kucerik, J. Hydration and water holding properties of cross-linked lignite humic acids. Geoderma 2014, 230-231, 151-160. [CrossRef]

22. Speltini, A.; Merlo, F.; Maraschi, F.; Sturini, M.; Contini, M.; Calisi, N.; Profumo, A. Thermally condensed humic acids onto silica as SPE for effective enrichment of glucocorticoids from environmental waters followed by HPLC-HESI-MS/MS. J. Chromatogr. A 2018, 1540, 38-46. [CrossRef]

23. Stathi, P.; Deligiannakis, Y. Humic acid-inspired hybrid materials as heavy metal adsorbents. J. Colloid Interface Sci. 2010, 351, 239-247. [CrossRef]

24. Yang, Y.-H.; Koopal, L.K. Immobilisation of humic acids and binding of nitrophenol to immobilised humics. Colloids Surf. A Physicochem. Eng. Asp. 1999, 151, 201-212. [CrossRef]

25. Fiol, N.; Villaescusa, I. Determination of sorbent point zero charge: Usefulness in sorption studies. Environ. Chem. Lett. 2009, 7, 79-84. [CrossRef]

26. Esteves, V.I.; Duarte, A.C. Thermogravimetric properties of aquatic humic substances. Mar. Chem. 1999, 63, 225-233. [CrossRef]

27. Francioso, O.; Montecchio, D.; Gioacchini, P.; Ciavatta, C. Thermal analysis (TG-DTA) and isotopic characterization of humic acids from different origins. Appl. Geochem. 2005, 20, 537-544. [CrossRef]

28. Ghimire, K.N.; Inoue, K.; Makino, K.; Miyajima, T. Adsorptive removal of arsenic using orange juice residue. Sep. Sci. Technol. 2002, 37, 2785-2799. [CrossRef]

29. Guo, H.; Stuben, D.; Berner, Z. Arsenic removal from water using natural iron mineral-quartz sand columns. Sci. Total Environ. 2007, 377, 142-151. [CrossRef] [PubMed]

30. Thirunavukkarasu, O.S.; Viraraghavan, T.; Subramanian, K.S. Removal of arsenic in drinking water by iron oxide-coated sand and ferrihydrite -batch studies. Water Qual. Res. J. 2001, 36, 55-70. [CrossRef]

31. Ansone, L.; Klavins, M.; Viksna, A. Arsenic removal using natural biomaterial-based sorbents. Environ. Geochem. Health. 2013, 35, 633-642. [CrossRef]

32. Kuriakose, S.; Singh, T.S.; Pant, K.K. Adsorption of As(III) from Aqueous Solution onto Iron Oxide Impregnated Activated Alumina. Wat. Qual. Res. J. Can. 2004, 39, 258-266. [CrossRef]

33. Ho, Y.-S.; Ofomaja, A.E. Kinetics and thermodynamics of lead ion sorption on palm kernel fibre from aqueous solution. Process Biochem. 2005, 40, 3455-3461. [CrossRef]

34. Mohan, D.; Pittman, C.U. Arsenic removal from water/ wastewater using adsorbents-A critical review. J. Haz. Mat. 2007, 142, 1-53. [CrossRef] [PubMed]

35. Visual MINTEQ 3.1. Available online: https://vminteq.lwr.kth.se/ (accessed on 2 August 2020).

36. National Library of Medicine. National Center of Biotechnology Information. PubChem. Chlorpromazine. Available online: https:/ / pubchem.ncbi.nlm.nih.gov / source/hsdb/3033\#section=Interactions-(Complete) (accessed on 2 August 2020).

37. Hai, J.; Bai, B.; Ding, C.; Wang, H.; Suo, Y. Removal of oil from water surface by novel composite NSM-g-P (MMA-co-BA) Super Oil absorption Resin. Polym. Compos. 2016. [CrossRef] 